\title{
A PHYSICAL MECHANISM OF SENSITIVITY ENHANCEMENT OF ORGANIC X-RAY DETECTORS WITH TUNGSTEN NANOPARTICLES
}

\author{
A. Poškus, R. Dobužinskas *, M. Viliūnas, and K. Arlauskas \\ Institute of Chemical Physics, Faculty of Physics, Vilnius University, Sauletekio 3, 10257 Vilnius, Lithuania \\ Email: rokas.dobuzinskas@ff.vu.lt
}

Received 19 November 2019; revised 22 January 2020; accepted 23 January 2020

\begin{abstract}
A simple theoretical model explaining the increase of X-ray sensitivity caused by adding tungsten nanoparticles into thin layers of organic materials is proposed. The mentioned increase of sensitivity is caused by quenched electron multiplication due to secondary electron emission from tungsten particles. After some simplifying assumptions, an expression of the electron multiplication factor $K$ is derived for the case when tungsten atoms are uniformly mixed with the matrix material. The main assumption of the model is the existence of a threshold energy $E_{\min }$ of the order of $0.1 \mathrm{eV}$, below which the recombination of charge carriers prevents them from being accelerated by the electric field to energies sufficient for impact ionization. It is shown that this assumption makes the increase of $K$ and photocurrent with increasing electric field much slower than the exponential increase commonly associated with an electron avalanche, and $K$ may even start to decrease when the electric field strength exceeds a certain value. Another factor, which has an adverse effect on the X-ray sensitivity, is the ionization energy loss of photoelectrons inside metallic nanoparticles. The results of Monte Carlo simulations show that in the case of spherical tungsten particles with $0.8 \mu \mathrm{m}$ diameter, the latter phenomenon may cause an additional decrease of the sensitivity by as much as $75 \%$. In order to reduce this effect, the size of nanoparticles should be reduced, or, alternatively, most of the photoelectrons should be generated in the organic matrix rather than inside the nanoparticles.
\end{abstract}

Keywords: hybrid organic-inorganic X-ray sensors, physical mechanism, Monte Carlo simulation PACS: 73.61.-r

\section{Introduction}

Organic thin film X-ray sensors are an emerging topic of organic electronics [1-7]. As demonstrated by recent applications of high sensitivity and signal-to-noise ratio organic devices, they can be used for efficient direct and indirect charge conversion of X-rays to electric current [8-11]. In addition, organic light emitting diodes (OLED) with organic field effect transistor arrays (OFET) are successfully applied for mobile devices, television and in flexible bio-compatible electronics [12-16], thus the organic X-ray imaging devices may also be immediately incorporated in the existing industry.
The production of organic functional films has important advantages over widespread silicon semiconducting technologies. Organic layers are mostly produced using solution processing techniques such as drop-casting, spin-coating and doctor blade [17-19]. These are applicable for fast production of large-area devices using roll-to-roll technologies under room conditions, making the manufacturing process vastly cheaper with a significant reduction of power consumption [20-23].

However, solution processing techniques have some disadvantages. The final layers are contaminated with trace amounts of solvents, degrading their electrical properties [24, 25]. Moreover, for 
the multilayer production different solvents need to be carefully selected, thus the production design becomes difficult and so the high-quality materials may never be applied. We proposed a new approach, the melt spin-coating (MSC) technique [26], where during a layer production the liquid phase is achieved by applying higher temperature $\left(\sim 100^{\circ} \mathrm{C}\right)$ to the material until it melts. Then the melt is spun to form the layer with a smooth surface. In such a way solvents are not used, and this may overcome the problems of using solvents [27, 28].

The X-ray absorption is characterized by the attenuation coefficient $X$ of a material $Z: X \sim Z^{4}$ / $E^{3}$, where $E$ is the $X$-ray photon energy and $Z$ is the atomic number. Thus, the coefficient $X$ strongly depends on the elemental composition of materials [29]. Organic compounds consist of low- $Z$ chemical elements (mostly carbon and hydrogen) and possess low X-ray absorption. To increase the absorption of X-rays, we incorporated heavy metallic particles into the organic bulk and produced hybrid organic-inorganic films. Recently, such approach was demonstrated to be successful by different researchers [30-33], but the complete physical mechanism of charge excitation and transfer in such films is still not known and has been little discussed. Moreover, the effect of distribution of X-ray absorbent particles in the organic bulk has not been widely considered, although it may also contribute to the optimization of such devices.

Recently, we investigated the films composed of three types of carbazolyl-containing molecules mixed with tungsten particles [34-37]. The X-ray induced signal and the electrical properties of the films varied depending on a type of the molecules. The differences of X-ray sensitivities of these hybrid films raised the questions concerning the physical mechanism of sensitivity and signal magnitude. Interestingly, the shape of distribution of tungsten particles was different in different organic materials. In the layers produced of molecules branched with carbazole, the clustering of tungsten particles occurs (for example, see Fig. 2 in [26). These effects underline the need for a deeper theoretical evaluation of X-ray absorption, charge transfer and the effect of tungsten particles on the X-ray-induced signal measured in these films.

In Refs. [8, 30, 33], the sensitivity is defined as the average charge collected from the unit volume divided by the average absorbed dose (i.e. by the av- erage energy absorbed per unit mass). As a result, differences of the sensitivity values obtained for different materials or for different thicknesses cannot be explained in terms of different rates of photogeneration of charge carriers alone: an increase of the photogeneration rate due to a greater attenuation quantum efficiency $(\mathrm{QE})$ is proportional to the corresponding increase of the absorbed dose rate, so the sensitivity would be independent of QE if the collected charge was equal to the photogenerated charge and if the photogenerated charge per unit absorbed energy was the same. Thus, there are two possible factors that can cause a change of sensitivity:

1) differences in the processes of charge carrier loss (for example, due to recombination) or additional generation sustained by sources of energy other than the incident $\mathrm{X}$-ray radiation (for example, secondary electron emission due to acceleration of electrons by electric field),

2) differences in the $W$ value of the material.

The $W$ value is defined as the average energy required to create an ion pair. It is known [38] that the $W$ values of organic materials composed of simple molecules are equal to (20-30) eV. Consequently, one should not observe a change of sensitivity greater than approximately $30 \%$ if the difference of $W$ values of the organic matrix was the main factor causing the differences of sensitivities (presence of high$Z$ nanoparticles cannot have a significant effect on the overall $W$ value of the layer, and this has been confirmed by Monte Carlo simulations). The actual relative differences of sensitivity measured in different layers of equal thickness and at equal applied voltage are frequently of the order of $100 \%$ [26]. Thus, those differences must be mainly caused by the first of the two mentioned factors, i.e. the charge carrier loss or additional generation. In particular, an increase of sensitivity may be a result of a more efficient charge collection (i.e. decrease of the recombination rate). However, if one compares the sensitivities of two thin layers differing by the mass fraction of high- $Z$ nanoparticles, but having the same organic matrix, equal thickness, and at the same applied voltage, then it is hardly possible that the recombination rate will differ by a large factor that is frequently observed. An alternative mechanism of the sensitivity change caused by addition of the high- $Z$ nanoparticles to the organic material is proposed in the present work. This change consists of two terms, one of which is positive, while another is negative: 
1) an increase of sensitivity due to the fieldstimulated secondary emission of charge carriers from the high- $Z$ nanoparticles,

2) a decrease of sensitivity due to the ionization energy losses of secondary electrons inside the bulk of metallic high- $Z$ nanoparticles.

A partial theoretical treatment of those two effects will be presented in Section 3. Before that, the experimental results are presented.

\section{Experiment}

Carbazolyl-containing molecular glasses 1,3-bis[6(carbazol-9-yl)-5-(carbazol-9-methyl)-2-hydroxy4-oxahexyloxy]benzene (2C), 1,3-bis[6-(carbazol9-yl)-5-(diphenylamino-N-methyl)-2-hydroxy4-oxahexyloxy]benzene (2Ph) and 1,3-bis[5-(3,6dibromocarbazol-9-methyl)-6-(carbazol-9-yl)2-hydroxy-4-oxahexyloxy]benzene (2CBr) were mixed with monocrystalline tungsten particles (Wp) and deposited by the melt spin-coating (MSC) technique. In all cases, the weight fraction of tungsten was 0.04 . The average diameter of the tungsten particles was $0.8 \mu \mathrm{m}$. The structural formulas of the organic matrix materials are shown in Fig. 1. The sample production diagram is shown in Fig. 2.
First, the glass substrates of a size of $10 \times 10 \mathrm{~mm}$ were pre-cleaned (I). Second, the aluminum electrode was vacuum evaporated with a thickness of $400 \mathrm{~nm}$ (II). Then the MSC method was applied for the deposition of hybrid organic-inorganic layers (III). The powder of carbazolyl-containing molecules mixed with Wp was placed on the substrate, then the mixture was melted down and spun at a desired frequency to form a uniform layer with a thickness of $25 \mu \mathrm{m}$. After the layer deposition, the sample was repeatedly put in a vacuum chamber to form top electrodes with a diameter of 3 and $1 \mathrm{~mm}$ wide path. The path width of $1 \mathrm{~mm}$ ensures a secure distance of the connections of filament wires between the top and bottom electrodes (V). The sample was encapsulated with paraffin wax and placed $10 \mathrm{~cm}$ from the X-ray source to avoid the possible influence of ionization effects on the signal.

The $I-V$ characteristics were measured using a transimpedance amplifier with $1 \mathrm{G} \Omega$ feedback resistor. The dependence of photocurrent $\left(I=I_{\mathrm{X} \text {-ray }}-\right.$ $\left.I_{\text {dark }}\right)$ on voltage, shown in Fig. 3, was calculated from $I-V$ characteristics, where $I_{\text {dark }}$ is the current measured in dark and $I_{\mathrm{X} \text {-ray }}$ is the current measured under exposure of X-rays. The measurements were performed using X-rays from a molybdenum target

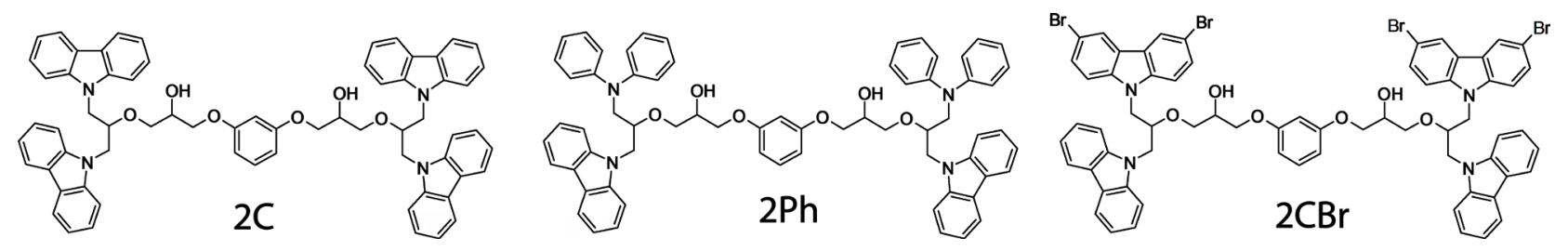

Fig. 1. Carbazolyl-containing molecules used in preparation of hybrid organic-inorganic films. 2C, 4 functional groups of carbazole; $2 \mathrm{Ph}, 2$ of phenyl and 2 of carbazole; $2 \mathrm{CBr}, 2$ of carbazole and 2 of carbazole functional groups with bromine branches.

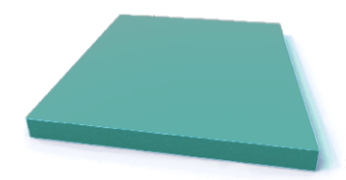

I

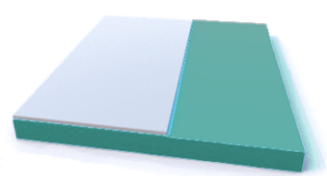

II

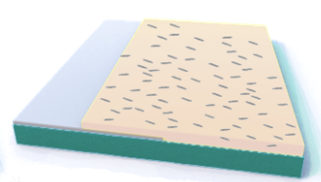

II

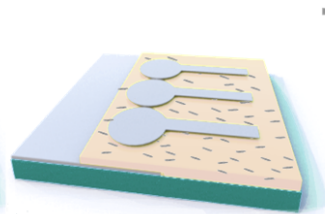

IV

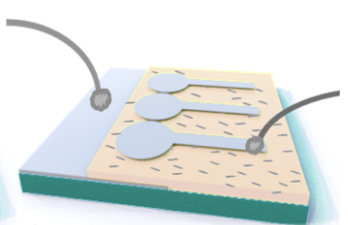

V

Fig. 2. Sample preparation diagram: I, pre-cleaned glass substrate; II, half-area vacuum evaporated aluminum electrode; III, a hybrid layer produced by MSC with a half-cleaned area of the bottom electrode; IV, vacuum evaporated top circle-shaped electrodes with $3 \mathrm{~mm}$ diameter and $1 \mathrm{~mm}$ width path; $\mathrm{V}$, sample with filament wires attached to the top (1) and bottom (2) electrodes. 


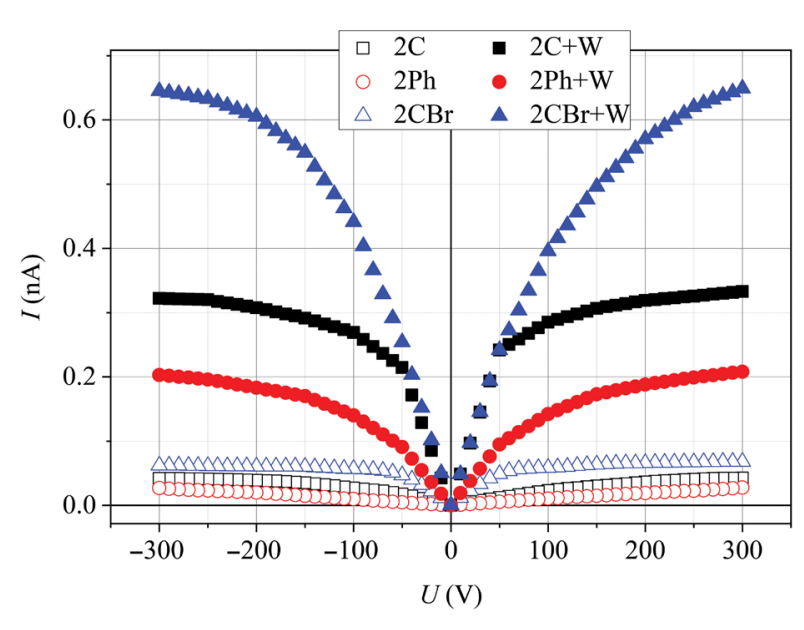

Fig. 3. Voltage dependence of the X-ray-induced photocurrent in the six investigated layers with a thickness of $25 \mu \mathrm{m}$ [26].

$\mathrm{X}$-ray tube under $35 \mathrm{kV}$ with $1 \mathrm{~mA}$ anode current. Approximately $40 \%$ of all incident X-ray photons correspond to the $17.5 \mathrm{keV} \mathrm{K}_{\alpha}$ line of characteristic Mo radiation. The flux of $\mathrm{K}_{\alpha}$ photons reaching the top electrode of a sample is approximately equal to $\Phi=2.4 \cdot 10^{9} \mathrm{~cm}^{-2} \mathrm{~s}^{-1}$. The remaining $60 \%$ of the total incident X-ray flux consists of characteristic $\mathrm{K}_{\beta}$ and $\mathrm{K}_{\gamma}$ radiation, as well as of bremsstrahlung photons with a continuous energy spectrum starting at approximately $5 \mathrm{keV}$ (photons with energies less than $5 \mathrm{keV}$ are practically completely absorbed in the glass of the X-ray tube) and ending at $35 \mathrm{keV}$.

Figure 3 presents the voltage dependence of the X-ray-induced photocurrent in the six layers with a thickness of $25 \mu \mathrm{m}$. Table 1 presents the maximum photocurrent densities $\left(j_{\text {exp max }}\right)$ measured for those layers, the corresponding values of the sen-

Table 1. Values of the maximum photocurrent and the corresponding sensitivity of six layers with a thickness of $25 \mu \mathrm{m}$ [26].

\begin{tabular}{c|c|c|c|c}
\hline Material & $\begin{array}{c}j_{\text {exp. max }} \\
\text { nA } \mathrm{cm}^{-2}\end{array}$ & $\begin{array}{c}j_{\text {th' }} \\
\mathrm{nA} \mathrm{cm}^{-2}\end{array}$ & $\begin{array}{c}j_{\text {th. hom, }} \\
\mathrm{nA} \mathrm{cm}^{-2}\end{array}$ & $\begin{array}{c}S, \\
\mathrm{nC} \mathrm{mGy}^{-1} \mathrm{~cm}^{-3}\end{array}$ \\
\hline $2 \mathrm{C}$ & 0.60 & 1.7 & - & 38 \\
\hline $2 \mathrm{Ph}$ & 0.39 & 1.7 & - & 25 \\
\hline $2 \mathrm{CBr}$ & 0.96 & 49.8 & - & 1.5 \\
\hline $2 \mathrm{C}+\mathrm{W}$ & 4.67 & 4.1 & 17.0 & 30 \\
\hline $2 \mathrm{Ph}+\mathrm{W}$ & 2.97 & 4.1 & 17.0 & 19 \\
\hline $2 \mathrm{CBr}+\mathrm{W}$ & 9.19 & 49.7 & 57.4 & 12 \\
\hline
\end{tabular}

sitivity $(S)$ and the theoretical current densities $\left(j_{\text {th }}\right.$ and $j_{\text {th. hom. }}$ ) calculated as described in Section 3. $j_{\text {th }}$ has been calculated by taking into account the ionization energy losses inside $\mathrm{Wp}$, whereas $j_{\text {th. hom. }}$ has been calculated for the case when those losses are negligible (i.e. a homogeneous mix of atoms, or extremely small nanoparticles). Both $j_{\text {th }}$ and $j_{\text {th. hom. }}$ have been calculated ignoring the effects of recombination and acceleration in the external electric field (because of the complexity of the simulations, and because the relevant material parameters are unknown). The uncertainty of the theoretical values of photocurrent presented in Table 1 is approximately $30 \%$ (mainly caused by uncertainty of the density of the matrix material, which was approximately equal to $2.5 \mathrm{~g} / \mathrm{cm}^{3}$ ).

Figure 4 presents the dependence of sensitivity on the electric field strength for the layers composed of $2 \mathrm{CBr}$ blended with $\mathrm{Wp}$ in the case of four values of the layer thickness.

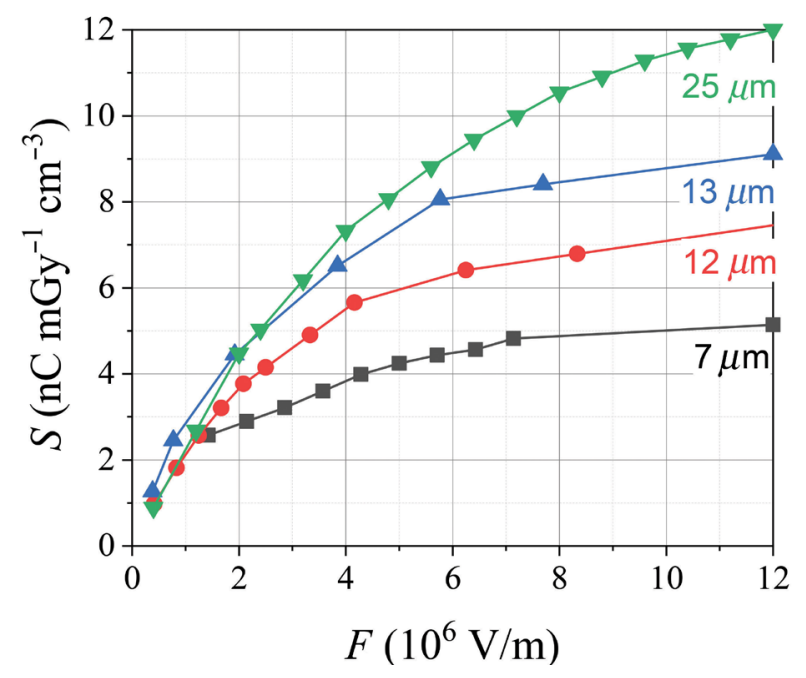

Fig. 4. Dependence of the X-ray sensitivity on electric field strength in the layers composed of $2 \mathrm{CBr}+\mathrm{W}$ with thicknesses of 7, 12, 13 and $25 \mu \mathrm{m}$.

\section{Discussion}

Since the theoretical photocurrent has been calculated neglecting charge carrier recombination, trapping and electric field effects, the theoretical values presented in Table 1 are significantly different from the experimental values. The fact that the experimental photocurrent is in most cases significantly less than the theoretical one, as well as the fact that the experimental photocurrent 
depends on the electric field strength in the entire range of voltages investigated in the present work (see Fig. 3) indicates that the charge carrier loss due to recombination has a strong influence on the measured current density. The mentioned recombination reduces the fraction of generated carriers that reach the electrodes, and this fraction increases with electric field strength. Accordingly, the photocurrent increases with increasing voltage. An especially large difference between the theoretical and experimental photocurrents is observed in the case of the layers containing $\mathrm{Br}$ (see Table 1). This means that the charge carrier loss due to recombination is more important in $2 \mathrm{CBr}$ than in $2 \mathrm{C}$ and $2 \mathrm{Ph}$. Another obvious difference between the experimental and theoretical results is a much larger relative increase of the measured photocurrent after adding tungsten particles into the layer in comparison with the relative increase predicted by simplified theoretical calculations (see Table 1). This discrepancy can be explained by the field-assisted impact ionization of tungsten atoms (as mentioned, electric field effects, including field-assisted ionization, have not been taken into account when calculating the theoretical photocurrent). A detailed discussion of the latter effect is presented in Subsection 3.1. The method of calculation of $j_{\text {th }}$, which takes into account the ionization energy losses inside the metallic nanoparticles (but does not take into account recombination and field effects), will be described in Subsection 3.2.

Near the thermal equilibrium (when charge carrier energies are of the order of $k T$ ), the electric current in organic materials is mainly caused by motion of holes. However, this fact is not important at much higher energies when the charge carriers are mainly generated by electron impact. Since the following discussion will deal mainly with kinetic energies of the order of $1 \mathrm{eV}$ or greater, the charge carriers will be assumed to be electrons. Moreover, since the role of chemical binding effects (including the band structure of charge carrier energy levels in the material) decreases with increasing energy, and bearing in mind that the theoretical model described below is intended to be only a crude approximation of the physical reality, all quantitative estimates will be done by treating the materials as collections of isolated neutral atoms.

\subsection{The effect of the field-assisted secondary emission from high-Z nanoparticles}

It is known that the recombination cross-section decreases with increasing electron energy. Consequently, the dominant interaction mechanisms of the electrons with energy $(E)$ of the order of $1 \mathrm{eV}$ are elastic scattering (defined by zero change of the electron energy during each collision) and impact ionization. The elastic scattering is by far the most probable interaction at $1 \mathrm{eV}<E<100 \mathrm{eV}$ [39], and it determines the free path. Tungsten has a lower ionization threshold $(7.8 \mathrm{eV})$ than the other elements present in the investigated layers. Among the latter elements, carbon has the lowest ionization threshold $(11.3 \mathrm{eV})$. Assuming that recombination and energy loss to other types of inelastic scattering are negligible, the electrons with energies less than the ionization threshold $E^{\prime}$ can be accelerated by the electric field to energies higher than $E^{\prime}$ and cause impact ionization. If two electrons existing after such an event are not lost to recombination and if their energy is not lost to other types of inelastic scattering, they will also be accelerated, so that an electron avalanche develops. The mean distance $\left(l_{\mathrm{i}}\right)$ travelled by an electron with zero initial energy before an impact ionization of a tungsten atom can be easily calculated assuming that:

1) tungsten atoms are uniformly mixed with the matrix material,

2) $l_{\mathrm{i}}$ is much greater than the free path $\lambda$ (the average distance between two elastic collisions),

3 ) elastic scattering is isotropic (this is approximately true when $E$ is of the order of a few $\mathrm{eV}$ ),

4) there are no other energy loss mechanisms.

As it follows from assumption 2, an electron experiences a very large number of elastic collisions before causing an impact ionization of a tungsten atom. As it follows from assumption 3, the change of the electron direction after each elastic collision is typically large (there is a $50 \%$ chance that the scattering angle will be greater than $90^{\circ}$ ). Consequently, the electron path is very erratic, and it stays inside a relatively small volume with linear dimensions that are much less than the total path (l) travelled by the electron. In the presence of an external electric field, the mentioned random motion is superimposed on the gradual drift of the electron in the direction of the external force. If the electron path is large enough, the displacement caused by 
the drift $(x)$ may become much greater than the lateral displacement due to the random motion. In such a case, the overall shape of the electron path becomes similar to a straight line parallel to the external force. However, microscopically, it includes a large number of random changes of the direction. This means that the total path travelled by the electron is much greater than the displacement due to the drift $(l \gg x)$.

Under those assumptions, the average path $\mathrm{d} l$ travelled by the electron during the infinitesimal period of time $\mathrm{d} t$ can be related to the average displacement $\mathrm{d} x$ along the direction of electric field by the equality

$$
\mathrm{d} l=\left(v / v_{\mathrm{dr}}\right) \mathrm{d} x,
$$

where $v$ is the total speed of the electron, and $v_{\mathrm{dr}}$ is the drift speed:

$$
v_{\mathrm{dr}}=\mu F .
$$

Here $\mu$ is the mobility and $F$ is the electric field strength (if $F$ is expressed in $\mathrm{V} / \mathrm{m}$, then its numerical value may be interpreted as the force exerted by the field on the electron in units of $\mathrm{eV} / \mathrm{m}$ ). As mentioned, $\mathrm{d} l \gg \mathrm{d} x$ because $v \gg v_{\mathrm{dr}}$. In Eq. (1), it is assumed that the displacement caused by drift (denoted by $\mathrm{d} x$ ) occurs over a very large number of elastic collisions, so that the random fluctuations average out and the net displacement has the same direction as the external force, although a single elastic collision may cause a temporary displacement in a different direction (for example, this happens when the electron is scattered in the direction opposite to the external force). Also, the displacement caused by drift is equal to

$$
\mathrm{d} x=\mathrm{d} E /(e F),
$$

where $\mathrm{d} E$ is the increase of the electron energy after its displacement by $\mathrm{d} x$ along the direction of the field, and $e$ is the elementary charge. The values of $v$ and $\mu$ are related to $E$ as follows:

$$
v=\sqrt{2 E / m} \text {. }
$$

Here $m$ is the electron mass, and

$$
\mu=e \lambda / \sqrt{2 E m},
$$

where $\lambda$ is the free path

$$
\lambda=1 / \Sigma_{\text {elast' }}
$$

and $\Sigma_{\text {elast }}$ is the macroscopic cross-section of elastic scattering, which depends on $E$. Using the tabulated electron scattering cross-sections for neutral atoms [39], it has been determined that the mentioned dependence is approximately a power function when $E$ is of the order of a few electronvolts:

$$
\Sigma_{\text {elast }}=\Sigma_{1} E^{-\alpha} \text {. }
$$

In the case of a homogeneous blend $2 \mathrm{CBr}+\mathrm{W}$ with a density of $2.5 \mathrm{~g} / \mathrm{cm}^{3}$ and a tungsten weight fraction of 0.04 , the exponent $\alpha$ is equal to 0.76 , and $\Sigma_{1}=7.19 \cdot 10^{8}$ (assuming that $E$ is expressed in electronvolts and $\Sigma_{\text {elast }}$ is expressed in $\mathrm{m}^{-1}$ ). By combining all equations presented above, the following relationship between $l$ and $E$ is obtained,

$$
\mathrm{d} l=\frac{1}{f} E^{\beta} \mathrm{d} E,
$$

or, equivalently,

$$
l=\frac{1}{f(1+\beta)} E^{1+\beta},
$$

where

$$
\beta=1-\alpha
$$

and

$$
f=\frac{F^{2}}{2 \Sigma_{1}}
$$

(it is assumed that $F$ is measured in $\mathrm{V} / \mathrm{m}$ ). If $F=1.2 \cdot 10^{7} \mathrm{~V} / \mathrm{m}$ (which corresponds to voltage of $300 \mathrm{~V}$ applied to a layer with $25 \mu \mathrm{m}$ thickness) and the other conditions are as indicated above, then $f \approx 1.0 \cdot 10^{5}$. The average path until impact ionization $\left(l_{\mathrm{i}}\right)$ can be calculated as follows:

$$
l_{\mathrm{i}}=\int_{0}^{\infty} l \frac{\mathrm{d} P}{\mathrm{~d} l} \mathrm{~d} l .
$$

Here $\mathrm{d} P / \mathrm{d} l$ is the probability density of the path $l$ at the moment of impact ionization. Because of the functional relationship (9) between $l$ and $E$, it 
is more convenient to use the average energy of the incident electron at the moment of impact ionization $\left(E_{\mathrm{i}}\right)$ instead of $l_{\mathrm{i}}$,

$$
E_{\mathrm{i}}=\int_{0}^{\infty} E \frac{\mathrm{d} P}{\mathrm{~d} E} \mathrm{~d} E
$$

where $\mathrm{d} P / \mathrm{d} E$ is the probability density of the electron energy $E$ at the moment of impact ionization:

$$
\begin{gathered}
\frac{\mathrm{d} P}{\mathrm{~d} E}=\frac{1}{f} \Sigma_{\text {ion }}(E) E^{\beta} \\
\times \exp \left[-\frac{1}{f} \int_{0}^{E} \Sigma_{\text {ion }}(y) y^{\beta} \mathrm{d} y\right] .
\end{gathered}
$$

Here $\Sigma_{\text {ion }}(E)$ is the macroscopic cross-section of impact ionization. The preexponential factor in Eq. (14) is equal to the probability density of impact ionization as a function of electron energy $E$, whereas the exponential factor is equal to the probability that the electron is accelerated from 0 to energy $E$ or greater before the impact ionization event (in other words, that its path is $l(E)$ or greater, where the function $l(E)$ is defined by Eq. (9)). The approximate value of $l_{\mathrm{i}}$ can be obtained by substituting $E_{\mathrm{i}}$ into Eq. (9).

The value of $l_{\mathrm{i}}$ corresponding to the ionization of tungsten atoms at the conditions indicated above is $155 \mu \mathrm{m}$. The value of $l_{\mathrm{i}}$ corresponding to the ionization of carbon $(\mathrm{C})$ atoms under the same conditions is $170 \mu \mathrm{m}$. The root mean square value of linear displacement of the electron during the same period due to random motion caused by multiple elastic scattering is equal to

$$
\Delta x=\sqrt{2 D t} \approx \sqrt{2 \lambda l_{\mathrm{i}} / 3},
$$

where $D=v \lambda / 3$ is the approximate diffusion coefficient (this expression of $D$ is valid in the case of isotropic elastic scattering), and $t=l_{\mathrm{i}} / v$ is the approximate time of acceleration. $\Delta x$ is equal to the size of the region that would contain most of the electron trajectory if there was no drift during the process of acceleration. Using the values of $l_{\mathrm{i}}$ mentioned above and assuming that $\lambda$ corresponds to kinetic energy of a few electronvolts, the value of $\Delta x$ calculated according to Eq. (15) is of the order of $0.1 \mu \mathrm{m}$. The displacement of the electron due to drift under the same conditions is of the order of $1 \mu \mathrm{m}$. Since these values of the displacement are much less than the layer thickness, impact ionization can be an important contribution to the total electric current. The mentioned values of $l_{\mathrm{i}}$ indicate that the impact ionization of tungsten is more probable than the impact ionization of the organic matrix.

Another factor to consider when discussing the possibility of an electron avalanche in an organic-inorganic blend is the energy of two electrons existing after an impact ionization event. This is because the cross-sections of inelastic scattering and recombination in the organic matrix are much greater at $E<1 \mathrm{eV}$ than at energies of the order of $1 \mathrm{eV}$ or greater. In particular, it is a well-known fact that the recombination cross-section increases when the electron speed is decreased. Consequently, if the charge carrier energy is less than approximately $1 \mathrm{eV}$, then acceleration to $E^{\prime}$ may become impossible. The calculations show that the electron energy $E_{\mathrm{i}}$ after travelling the path $l_{\mathrm{i}}$ at the conditions indicated above exceeds $E^{\prime}$ by $3.1 \mathrm{eV}$ in the case of ionization of tungsten, and by $0.45 \mathrm{eV}$ in the case of ionization of $\mathrm{C}$ (difference of the latter two values is caused by much higher concentration of $\mathrm{C}$ in comparison with that of tungsten). The mentioned value of $E_{\mathrm{i}}-E^{\prime}$ is equal to the average total energy of the two electrons existing after an impact ionization event. Thus, impact ionization of the organic matrix cannot cause an electron avalanche (intense inelastic scattering prevents further acceleration of two low-energy electrons existing after an impact ionization of the organic matrix). For the same reason, the electron avalanche does not occur without exposure to X-ray radiation: intense inelastic scattering (including the process of recombination) keeps the energy of charge carriers at values of the order of $k T$ even in the case of a relatively strong electric field. In contrast, the energies of two electrons existing after an impact ionization of tungsten belong to the high-energy range $(E \sim 1 \mathrm{eV})$, where the acceleration to $E^{\prime}$ is possible, so that an electron avalanche develops.

As it is clear from the discussion presented above, the effect of the impact ionization of tungsten atoms under the mentioned assumptions is qualitatively different from the effect of the impact ionization of the organic matrix. The former 
can potentially lead to an electron avalanche and a consequent exponential growth of the photocurrent with increasing electric field strength, whereas the latter can only cause an increase of the current by a factor of two at most (due to creation of two low-energy electrons, which cannot cause further impact ionization). The overall dependence of the photocurrent on the electric field strength is a result of a 'competition' between these two processes. The mentioned dependence is approximately equal to the product of the photocurrent observed in absence of the field-stimulated electron multiplication, and of the multiplication factor $(K)$ reflecting the latter effect. The approximate calculation of $K$ is presented below.

In accordance with the previous discussion, it will be assumed that the energy dependence of the macroscopic cross-section of electron inelastic scattering consists of three regions (see Fig. 5): (I) the low-energy region $\left(E<E_{\min }\right)$, where inelastic interactions are extremely frequent and prevent a significant acceleration in an electric field, (II) the range $E_{\text {min }}<E<E^{\prime}$, where the inelastic collisions are relatively infrequent and do not interfere with acceleration in an electric field, (III) the range $E>E^{\prime}$, where impact ionization is significant. The ionization threshold $E^{\prime}$ is defined separately for the tungsten atoms $\left(E_{\mathrm{W}}^{\prime}\right)$ and the organic matrix $\left(E_{\mathrm{org}}^{\prime}\right)$. In Fig. 5 ,

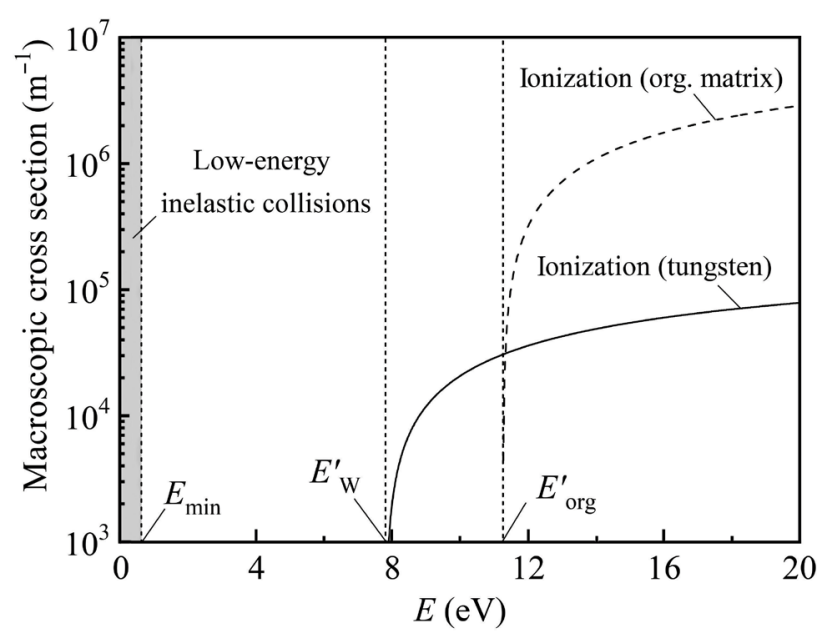

Fig. 5. Approximate dependence of the macroscopic cross-section of inelastic scattering on electron energy in the case of a homogeneous blend $2 \mathrm{CBr}+\mathrm{W}$ with a density of $2.5 \mathrm{~g} / \mathrm{cm}^{3}$ and a tungsten weight fraction of 0.04 . it is assumed that $E_{\min }=0.6 \mathrm{eV}, E_{\mathrm{w}}^{\prime}=7.8 \mathrm{eV}$ and $E_{\text {org }}^{\prime}=11.26 \mathrm{eV}$ (the latter value is the ionization threshold of atomic carbon). The value of $E^{\prime}$ mentioned above is the smallest of the latter two ionization thresholds, i.e. $E^{\prime}=E_{\mathrm{w}^{\prime}}^{\prime}$ If $E$ belongs to range II, then the electron may be accelerated by electric field to energy $E>E^{\prime}$ and may cause impact ionization of a tungsten atom or of a molecule of the organic matrix. Energies of the two electrons existing after such an event may be assumed to be uniformly distributed between 0 and $E-E_{\mathrm{W}}^{\prime}$ or between 0 and $E-E_{\text {org' }}^{\prime}$, respectively [39]. Consequently, there is a nonzero probability that the energy of one or both of those electrons is less than $E_{\min }$. Those electrons will be lost from the avalanche. Thus, two types of electrons are created during the electron multiplication process: high-energy electrons with energy greater than $E_{\text {min }}$, which can cause impact ionization (their number will be denoted by $N_{\mathrm{h}}$ ), and low-energy electrons with energy less than $E_{\min }$, which drift in the external field without causing impact ionization (their number will be denoted by $N_{\text {low }}$ ). The average change of $N_{\mathrm{h}}$ due to a single impact ionization event will be denoted by $\gamma$ (its possible values are from -1 to 1 ). If the average displacement of the electron along the $X$ axis (parallel to the electric field) until an impact ionization is equal to $x_{i}$, then the value of $N_{h}$ depends on $x$ according to the equation

$$
\frac{\mathrm{d} N_{h}}{\mathrm{~d} x}=\frac{\gamma N_{h}}{x_{\mathrm{i}}},
$$

i.e.

$$
N_{\mathrm{h}}(x)=\exp \left(\frac{\gamma}{x_{\mathrm{i}}} x\right)
$$

(since the aim is calculation of the multiplication factor, the initial condition is $\left.N_{h}(0)=1\right)$. The average change of $N_{\text {low }}$ due to a single impact ionization is equal to $1-\gamma$, because the total change of the number of electrons is equal to 1 . Consequently, the value of $N_{\text {low }}$ depends on $x$ according to the equation

$$
\frac{\mathrm{d} N_{\text {low }}}{\mathrm{d} x}=\frac{(1-\gamma) N_{\mathrm{h}}}{x_{\mathrm{i}}},
$$


i.e.

$$
\begin{aligned}
& N_{\text {low }}(x)=\frac{1-\gamma}{x_{\mathrm{i}}} \int_{0}^{x} N_{\mathrm{h}}\left(x^{\prime}\right) \mathrm{d} x^{\prime} \\
& =\left(\frac{1}{\gamma}-1\right)\left[\exp \left(\frac{\gamma}{x_{1}} x\right)-1\right] \\
& =\left(\frac{1}{\gamma}-1\right)\left[N_{\mathrm{h}}(x)-1\right] .
\end{aligned}
$$

The total number of electrons is equal to

$$
\begin{aligned}
& N(x)=N_{\mathrm{h}}(x)+N_{\text {low }}(x)= \\
& \frac{1}{\gamma}\left(N_{\mathrm{h}}-1\right)+1=\frac{1}{\gamma} \exp \left(\frac{\gamma}{x_{\mathrm{i}}} x\right)-\frac{1}{\gamma}+1 .
\end{aligned}
$$

In the case of uniform photogeneration, the initial electron can be created at any depth with equal probability. This means that the total displacement $x$ is uniformly distributed from 0 to the layer thickness $d$. In such a case, the electron multiplication factor is equal to

$$
\begin{aligned}
& K=\frac{1}{d} \int_{0}^{d} N(x) \mathrm{d} x= \\
& \frac{x_{\mathrm{i}}}{\gamma^{2} d}\left[\exp \left(\frac{\gamma}{x_{\mathrm{i}}} d\right)-1\right]-\frac{1}{\gamma}+1 .
\end{aligned}
$$

The value of $x_{\mathrm{i}}$ is proportional to the average change of the electron energy between two impact ionization events:

$$
x_{\mathrm{i}} \approx \frac{E_{\mathrm{i}}-E_{\mathrm{sec}}}{F} .
$$

Here $E_{\mathrm{i}}$ is the average energy of the incident electron at the moment of impact ionization, $E_{\text {sec }}$ is the average energy of either of the two secondary electrons existing after an impact ionization event, and $F$ is the electric field strength (energies are assumed to be expressed in $\mathrm{eV}$, and $F$ is assumed to be expressed in $\mathrm{V} / \mathrm{m}$, so that the value of $x_{\mathrm{i}}$ is obtained in units of $\mathrm{m}$ ). Thus, three quantities have to be known in order to be able to calculate the multiplication factor: $\gamma, E_{\mathrm{i}}$ and $E_{\text {sec }}$. For calculating the dependence of $K$ on $F$, the value of $\gamma$ is the most important, because its dependence on $F$ is strongest. Thus, the dependence of $K$ on $F$ is governed by the approximate relationship $x_{\mathrm{i}} \sim F^{-1}$ (see Eq. (22)), and by the dependence $\gamma(F)$. The calculation of $\gamma, E_{\mathrm{i}}$ and $E_{\mathrm{sec}}$ is straightforward if the energy dependences of the macroscopic cross-sections of impact ionization of tungsten and the organic matrix $\left(\Sigma_{\mathrm{W}}\right.$ and $\Sigma_{\mathrm{org}}$, respectively) are known. Those dependences are shown in Fig. 5 by solid and dashed lines, respectively, for the case of a homogeneous blend $2 \mathrm{CBr}+\mathrm{W}$ with a density of $2.5 \mathrm{~g} / \mathrm{cm}^{3}$ and a tungsten weight fraction of 0.04 .

The main quantity that has to be known for those calculations is the electron energy probability density $(\mathrm{d} P / \mathrm{d} E)$, which defines the probability for the electron energy at the moment of impact ionization to be inside any predefined interval. The expression of $\mathrm{d} P / \mathrm{d} E$, which follows from the assumption that the macroscopic crosssection of elastic scattering is equal to $\Sigma_{1} E^{\beta-1}$ and is much greater than the total macroscopic crosssection of all other types of interaction, is given by Eq. (14). In that expression, $\Sigma_{\text {ion }}(E)$ is a sum of two terms corresponding to impact ionization of tungsten and of the organic matrix:

$$
\Sigma_{\text {ion }}(E)=\Sigma_{\mathrm{w}}(E)+\Sigma_{\text {org }}(E)
$$

The expression of $\gamma$ is the following:

$$
\gamma=\int_{0}^{\infty} N^{\prime}(E) \frac{\mathrm{d} P}{\mathrm{~d} E} \mathrm{~d} E-1 .
$$

Here $N^{\prime}(E)$ is the average number of electrons with energy greater than $E_{\min }$ after a single impact ionization event caused by an electron with energy $E . N^{\prime}(E)$ is a weighted average of the two numbers corresponding to ionization of tungsten and of organic matrix $\left(N_{\mathrm{w}}\right.$ and $\left.N_{\mathrm{org}}\right)$ :

$$
N^{\prime}(E)=\frac{\Sigma_{\mathrm{W}}(E) N_{\mathrm{W}}(E)+\Sigma_{\mathrm{org}}(E) N_{\mathrm{org}}(E)}{\Sigma_{\mathrm{W}}(E)+\Sigma_{\mathrm{org}}(E)}
$$

$N_{\mathrm{w}}(E)$ and $N_{\text {org }}(E)$ are the average numbers of electrons with energy above $E_{\min }$ after the ionization of tungsten and of the organic matrix, respectively. Those two numbers can be easily obtained from the mentioned assumption that the energy distributions of the secondary electrons are uniform: 


$$
\begin{aligned}
& N_{\mathrm{W}}(E)=2\left(1-\frac{E_{\text {min }}}{E-E_{\mathrm{W}}^{\prime}}\right) \quad\left(E>E_{\mathrm{W}}^{\prime}+E_{\text {min }}\right), \\
& N_{\text {org }}(E)=2\left(1-\frac{E_{\text {min }}}{E-E_{\text {org }}^{\prime}}\right) \quad\left(E>E_{\text {org }}^{\prime}+E_{\text {min }}\right) .
\end{aligned}
$$

The fact that $N^{\prime}$ is a weighted average of $N_{\mathrm{W}}$ and $N_{\text {org }}$ (see Eq. (25)) is crucial for the dependence $\gamma(F)$, because an increase of electric field causes an increase of $E_{\mathrm{i}}$, i.e. of the typical values of the electron energy $E$, which contribute most to the integral in Eq. (24) (mathematically, this is caused by the decrease of the factor $1 / f$ in the exponent of Eq. (14)). When $E_{\mathrm{i}}$ becomes close to $E^{\prime}{ }_{\text {org }}$ or greater, the typical values of $\Sigma_{\text {org }}$ become much greater than $\Sigma_{\mathrm{W}}$ (see Fig. 5). This means that the typical values of $N^{\prime}$ become close to $N_{\text {org }}$ (see Eq. (25)). Those values are much less than $N_{\mathrm{w}}$ due to the fact that $E-E^{\prime}{ }_{\text {org }}$ is much less than $E-E^{\prime}{ }_{\mathrm{w}}$ (see Eq. (26)), i.e. after ionization of the organic matrix, one or both electrons are much more likely to have energy less than $E_{\min }$. Physically, this is a result of the fact that an electron with energy just above $E^{\prime}$ org does not have enough time for a significant acceleration and undergoes an inelastic collision with a molecule of the organic matrix almost immediately because of a large value of $\Sigma_{\text {org }}$. This causes a decrease of $\gamma$ at sufficiently strong fields. If this decrease counteracts the decrease of $x_{i}$ with increasing $F$, the multiplication factor $K$ starts to decrease. This could explain why the dependence of photocurrent on voltage is not exponential (see Fig. 3): the electron multiplication is 'quenched' due to increased frequency of electron inelastic interactions with the organic matrix and the consequent rapid 'conversion' of high-energy electrons to lowenergy electrons.

It should be noted that the 'quenching' process is not required to be impact ionization. It could also be excitation, with the condition that its macroscopic cross-section above the excitation energy $\left(E_{\text {exc }}\right)$ is sufficiently large, so that the loss of the energy amount $E_{\text {exc }}$ during the excitation is likely to make the electron energy less than $E_{\min }$. In this case, $N_{\text {org }}(E)$ is equal to 1 when $E>E_{\text {exc }}+E_{\text {min }}$, and to 0 when $E<E_{\mathrm{xc}}+E_{\text {min }}$.

Figure 6 presents the dependence of the multiplication factor $K$ on electric field strength at the conditions corresponding to Fig. 5, and at
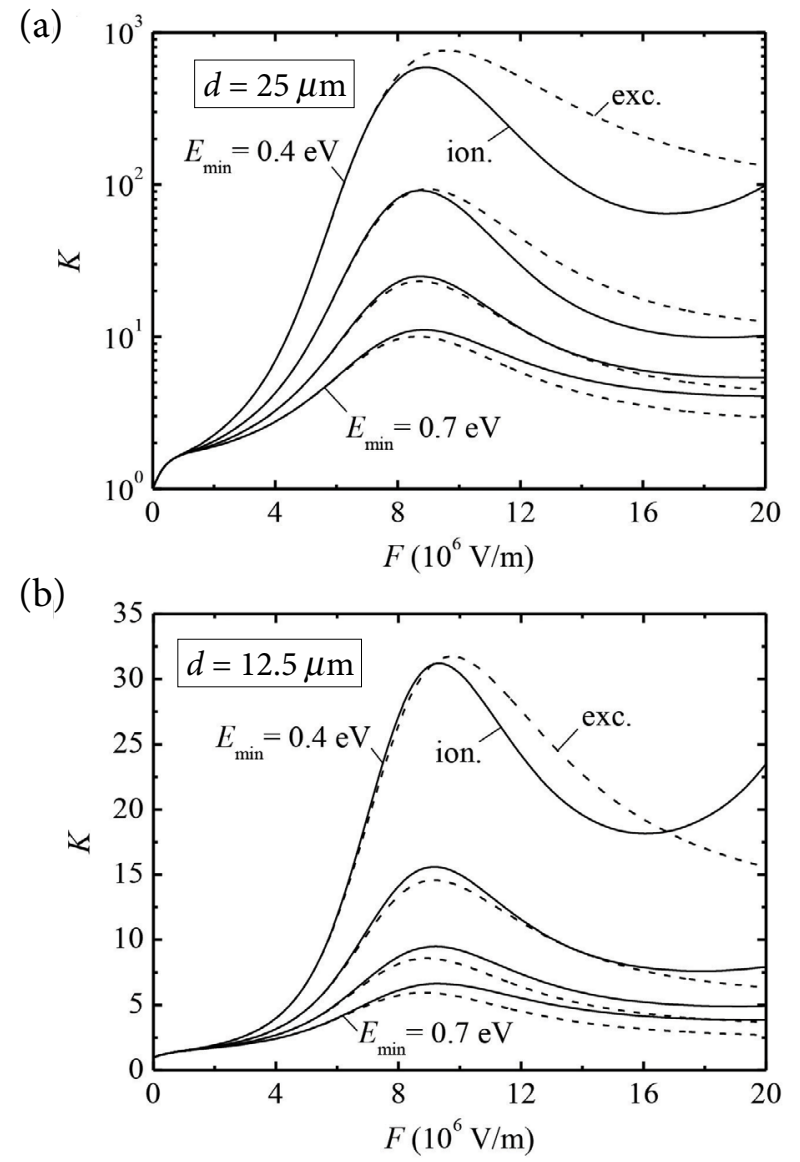

Fig. 6. Theoretical dependence of the multiplication factor $K$ on electric field strength in the case of a homogeneous blend $2 \mathrm{CBr}+\mathrm{W}$ with a density of $2.5 \mathrm{~g} / \mathrm{cm}^{3}$ and a tungsten weight fraction of 0.04 , for two values of the layer thickness: (a) $d=25 \mu \mathrm{m}$, (b) $d=12.5 \mu \mathrm{m}$. Solid lines correspond to the case when the quenching process is impact ionization of the organic matrix, and dashed lines correspond to the case when the quenching process is excitation with the excitation energy equal to $E^{\prime}$ org and the cross-section equal to $\Sigma_{\text {org }}$ (shown by a dashed line in Fig. 5). Four pairs of curves are shown, corresponding to $E_{\min }=0.4,0.5,0.6$ and $0.7 \mathrm{eV}$.

four equidistant values of $E_{\text {min }}$ from 0.4 to $0.7 \mathrm{eV}$. In those calculations, the impact ionization crosssections have been approximated by the expression

$$
\sum_{\text {ion }}(E)=B \ln \left(E / E^{\prime}\right) \quad\left(E>E^{\prime}\right),
$$

where $B=83500 \mathrm{~m}^{-1}, E^{\prime}=7.8 \mathrm{eV}$ in the case of tungsten, and $B=5 \cdot 10^{6} \mathrm{~m}^{-1}, E^{\prime}=11.26 \mathrm{eV}$ in the case of organic matrix, i.e. carbon. Both values of $E^{\prime}$ were obtained from [40]. The two mentioned values of $B$ were obtained by fitting the data of [39] and [40], respectively. Using the approximation 
(27), the integral in Eq. (14) can be expressed analytically. Consequently, calculation of the weighted integrals of $\mathrm{d} P / \mathrm{d} E$, which have to be calculated in order to estimate $\gamma, E_{\mathrm{i}}$ and $E_{\text {sec }}$ (see Eqs. (13) and (24)), requires only a single numerical quadrature.

Clearly, the assumption of complete absence of inelastic collisions (including the process of recombination) in the energy range $E_{\min }<E<E^{\prime}$ is not realistic. In a real material, the cross-sections of inelastic scattering and recombination are smooth functions of electron energy $(E)$, which are never exactly equal to zero. For example, the electron energy loss due to bremsstrahlung is possible at any energy (although its cross-section decreases with decreasing $E$ ). The mentioned energy range should be interpreted as the range, where the average electron energy loss due to inelastic collisions is much less than the average energy gain due to acceleration in the electric field. The exact shape of the dependence $K(F)$ is determined by the dependence of the mentioned cross-sections on $E$, and it is likely that the dependence of the exact $K$ on $F$ deviates significantly from the theoretical curves shown in Fig. 6. The purpose of these curves is only to demonstrate that the dependence of the electron multiplication factor on electric field strength may be much slower than the exponential increase, which is commonly associated with an electron avalanche, and to explain why we do not see an exponential growth of the photocurrent with voltage in Fig. 3.

Since the discussion and calculations presented above are based on the assumption that tungsten atoms are distributed uniformly, the results are not entirely applicable in the case of tungsten particles with a diameter of the order of $100 \mathrm{~nm}$ or greater. However, some qualitative predictions (such as the mentioned quenching effect) should be also valid in the latter case. The agreement between the experimental data and the calculation results presented above should improve with decreasing the size of tungsten particles.

\subsection{The effect of ionization energy losses inside metallic nanoparticles}

The difference of the values in the third and fourth columns of Table 1 demonstrates the importance of the electron energy loss inside the tungsten particles. Although the photoelectrons created by absorption of the photons emitted by a Mo X-ray tube with $35 \mathrm{kV}$ anode voltage have the average energy of (6-7) keV, the secondary electrons ('knock-on electrons'), which are emitted from the atoms of the material during the gradual slowing down of each photoelectron, have typically a much lower energy of the order of $10 \mathrm{eV}$. Those electrons are usually stopped inside the bulk of Wp and do not contribute to the photocurrent (because there is no electric field inside metallic nanoparticles). Thus, most of the electrons contributing to the photocurrent are created by impact ionization of the organic matrix. The number of those electrons is proportional to the average energy absorbed in the organic matrix (rather than in Wp). Since the generation of photoelectrons is approximately uniform over the entire bulk of a tungsten particle, the energy lost in tungsten particles increases with their diameter (presumably, clustering of Wp has a similar effect). In the case of $2 \mathrm{CBr}+\mathrm{W}$, the mentioned energy loss is relatively unimportant because the photoelectrons are mainly generated in the $\mathrm{Br}$ atoms. Consequently, the difference of $j_{\text {th. hom. }}$ and $j_{\text {th }}$ in the case of $2 \mathrm{CBr}+\mathrm{W}$ is relatively small (see Table 1). In the case of $2 \mathrm{C}+\mathrm{W}$ and $2 \mathrm{Ph}+\mathrm{W}$, the photoelectrons are mainly generated inside $\mathrm{Wp}$, and these electrons lose approximately $75 \%$ of their energy in a tungsten particle before escaping into the matrix. As a result, the number of secondary electrons generated by impact ionization in the matrix is reduced by a factor of 4 in comparison with the homogeneous material, and the theoretical photocurrent is reduced by the same factor (see Table 1).

The theoretical values of the photocurrent, which are presented in columns 3 and 4 of Table 1 , have been calculated by Monte Carlo simulation of coupled electron-photon transport (the electron and photon interaction cross-sections that have been used for the Monte Carlo simulations have been taken from [39] and [41], respectively, and the atomic relaxation data have been taken from [42]). A more detailed description of the calculation procedure is presented below.

The four main factors determining the rate of electron generation in the layer due to photoelectric absorption are the following:

(a) spectrum of the incident $\mathrm{X}$-ray radiation,

(b) mass absorption coefficient of the layer,

(c) mass thickness of the layer,

(d) average energy required to produce an ion pair (it will be further denoted by $W$ ). 
The mentioned spectrum is shown in Fig. 7 (a), and the mass photoelectric absorption coefficients of the matrix materials and the tungsten filler are shown in Fig. $\nabla(b)$.

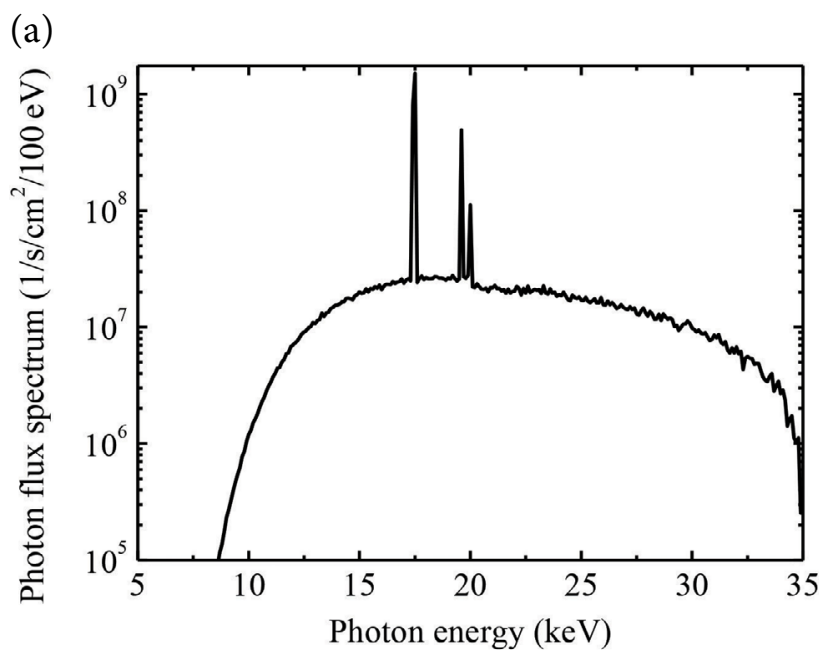

(b)

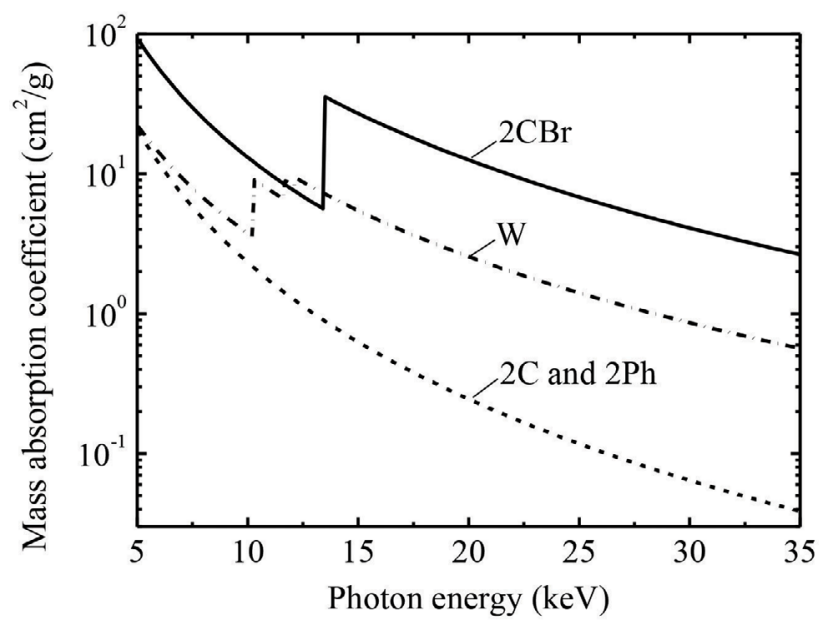

Fig. 7. (a) The calculated photon flux spectrum of the incident $\mathrm{X}$-ray radiation. (b) The mass photoelectric absorption coefficients of the organic matrix (2C, $2 \mathrm{Ph}, 2 \mathrm{CBr}$ ) and the tungsten filler (W).

The X-ray-induced current is proportional to the electron generation rate multiplied by the fraction of electrons that were not lost to recombination and trapping inside the layer. The electron generation rate (per unit mass of the layer material) at a given depth $x$ is equal to

$$
g(x)=A(x) / W,
$$

where $A$ is the energy absorption rate (per unit mass of the layer material). The energy absorption rate $A(x)$ consists of two terms:
1) energy of the secondary radiation from tungsten particles due to absorption of X-rays in them (assuming that this secondary radiation is completely absorbed in the organic matrix),

2) energy of the primary X-ray photons absorbed in the organic matrix.

Photoelectric absorption of X-rays in tungsten particles produces fast electrons and secondary characteristic X-ray radiation (the so-called ' $\mathrm{X}$-ray fluorescence'). However, most of the energy of the X-ray fluorescence radiation escapes from the layer due to high photon energy (greater than $8 \mathrm{keV}$ in the case of tungsten). The contribution of $\mathrm{K}_{\alpha}$ and $\mathrm{K}_{\beta} \mathrm{X}$-ray fluorescence radiation from $\mathrm{Br}$ atoms (photon energies 11.9 and $13.29 \mathrm{keV}$, respectively) to the photocurrent is also negligible. In contrast, the energy of fast electrons is practically completely absorbed in the matrix (because of their short range). The mentioned escape of X-ray fluorescence photons from the layer can therefore be taken into account by modifying Eq. (28) as follows:

$$
g(x)=\frac{1}{W}\left(A_{\mathrm{W}}(x)+A_{\text {matrix }}(x) f\right) .
$$

$A_{\mathrm{w}}$ is the energy of electrons released from $\mathrm{Wp}$ (per unit time and unit mass of the layer material), $A_{\text {matrix }}$ is the energy of the incident X-ray photons that were absorbed in the matrix per unit time and unit mass of the layer material, and $f$ is the fraction of that energy that was converted to energy of fast electrons (i.e. that was not re-emitted from the layer in the form of secondary X-ray radiation). The energy loss due to escape of highenergy X-ray fluorescence photons caused by photoelectric absorption in the organic material is significant only when the matrix contains high- $Z$ atoms. This means that for $2 \mathrm{C}$ and $2 \mathrm{Ph}, f \approx 1$. For $2 \mathrm{CBr}$, which contains $\operatorname{Br}(Z=35), f<1$. The value of $f$ for $2 \mathrm{CBr}$ has been calculated by the Monte Carlo simulation of a $25 \mu \mathrm{m}$-thick homogeneous layer of $2 \mathrm{CBr}$ with a density of $2.5 \mathrm{~g} / \mathrm{cm}^{3}$ exposed to a normally incident beam of $\mathrm{X}$-ray radiation. After simulating interaction of $10^{7}$ source photons with the layer, it has been determined that the total absorbed energy is $E_{\mathrm{abs}}=1.1 \cdot 10^{10} \mathrm{eV}$, and the total energy of the escaping $\mathrm{Br} \mathrm{K}_{\alpha}$ and $\mathrm{K}_{\beta} \mathrm{X}$ ray fluorescence photons is $E_{\text {loss }}=5.0 \cdot 10^{9} \mathrm{eV}$. This means that $f=E_{\mathrm{abs}} /\left(E_{\mathrm{abs}}+E_{\mathrm{loss}}\right) \approx 0.7$.

The value of $A_{\mathrm{w}}$ in Eq. (29) can be expressed as follows: 


$$
A_{\mathrm{W}}(x)=\int_{0}^{\infty} \Phi_{E^{\prime}}(x) \mu_{\mathrm{W}}\left(E^{\prime}\right) \bar{E}_{E^{\prime}} \mathrm{d} E^{\prime} .
$$

Here $\Phi_{E^{\prime}}(x)$ is the spectral photon flux density (shown in Fig. $\mathbb{Z}(\mathrm{a})$ for $x=0$ ), $\mu_{\mathrm{w}}\left(E^{\prime}\right)$ is the mass photoelectric absorption coefficient in tungsten for photon energy $E^{\prime}$, and $\bar{E}_{E^{\prime}}$ is the average total energy of all electrons released from a single tungsten particle after absorption of a single photon with energy $E^{\prime}$ in it. The values of $\bar{E}_{E^{\prime}}$ have been determined in the present work by performing Monte Carlo simulations of electron release from a sphere of tungsten with a diameter of $0.8 \mu \mathrm{m}$ placed into a uniform unidirectional flux of photons with a fixed energy, which was varied from 5 to $35 \mathrm{keV}$ in increments of $1 \mathrm{keV}$.

The value of $A_{\text {matrix }}$ in Eq. (29) can be expressed using a formula similar to Eq. (30),

$$
A_{\text {matrix }}(x)=\int_{0}^{\infty} \Phi_{E^{\prime}}(x) \mu_{\text {matrix }}\left(E^{\prime}\right) E^{\prime} \mathrm{d} E^{\prime},
$$

where $\mu_{\text {matrix }}\left(E^{\prime}\right)$ is the mass photoelectric absorption coefficient in the organic matrix for photon energy $E^{\prime}$.

The experimental values of $W$ for the nine simplest hydrocarbons, as well as for $\mathrm{CH}_{3} \mathrm{OH}$ and $\mathrm{C}_{2} \mathrm{H}_{5} \mathrm{OH}$, are tabulated on p. 28 of [38], and they range from $22 \mathrm{eV}\left(\right.$ for $\left.\mathrm{C}_{6} \mathrm{H}_{6}\right)$ to $27 \mathrm{eV}$ (for $\left.\mathrm{CH}_{4}\right)$. The values of $W$ have also been calculated in the present work by the Monte Carlo simulation of a monoenergetic electron source in an infinite medium with the same composition as the matrix materials investigated in the present work. Those calculations were performed at two electron energies: 5 and $35 \mathrm{keV}$, by the method described in [43]. For both energies and for all three matrix materials, the calculated values of $W$ are similar, and they range from 23 to $24 \mathrm{eV}$. Consequently, the value of $W$ in Eq. (29) will be assumed to be equal to $23.5 \mathrm{eV}$.

The theoretical photocurrent density (which corresponds to absence of recombination and trapping of charge carriers, as well as absence of any field effects) is equal to

$$
j_{\text {th }}=e \bar{g} d \rho,
$$

where $e$ is the elementary charge, $\bar{g}$ is the average value of the electron generation rate (3.29) in the lay- er, $d$ is the layer thickness, and $\rho$ is the layer density. The layer thickness is $25 \mu \mathrm{m}$, and the density of all three matrix materials is equal to $2.5 \pm 0.5 \mathrm{~g} / \mathrm{cm}^{3}$. The corresponding density of the layers containing Wp with a mass fraction of 0.04 is equal to $2.59 \mathrm{~g} /$ $\mathrm{cm}^{3}$. The values of $j_{\text {th }}$ obtained by substituting Eq. (29) into Eq. (32), along with the corresponding theoretical values of the photocurrent density in a homogeneous material $\left(j_{\text {th. hom. }}\right)$ and experimental maximum values of the photocurrent density $\left(j_{\text {exp. max }}\right)$, are presented in Table 1 .

\subsection{Interpretation of the experimental differences of sensitivity in terms of the theoretical model}

The fact that in the case of $2 \mathrm{C}+\mathrm{W}$ and $2 \mathrm{Ph}+\mathrm{W}$ layers the photoelectrons are mainly generated inside tungsten particles reduces the effectiveness of the field-assisted impact ionization, hence the sensitivity of those layers is even less than the sensitivity of pure $2 \mathrm{C}$ and $2 \mathrm{Ph}$ (see Table 1). Still, this decrease of sensitivity is not as pronounced as expected from the energy loss inside the tungsten particles alone: according to Table 1, if there was no additional change of sensitivity caused by charge carrier multiplication in the electric field, then the sensitivity of $2 \mathrm{C}+\mathrm{W}$ and $2 \mathrm{Ph}+\mathrm{W}$ would be less than the sensitivity of the pure matrix material by a factor greater than 4 (because such is the value of $j_{\text {th. hom. }}\left(j_{\text {th }}\right)$. This demonstrates that the mechanism of quenched electron multiplication described in Subsection 3.1 is important not only in $2 \mathrm{CBr}+\mathrm{W}$ but also in $2 \mathrm{C}+\mathrm{W}$ and $2 \mathrm{Ph}+\mathrm{W}$, and one could expect a significant increase of sensitivity of those layers if the size of tungsten nanoparticles was reduced.

The two competing processes (charge carrier recombination and multiplication) that are responsible for the observed differences of sensitivity are both characterized by a strong dependence on the electric field strength and on the layer thickness:

1) increase of electric field strength causes a decrease of the average recombination rate (because the charge carriers have a greater drift velocity and reach the electrodes in a shorter time) and an increase of the multiplication factor $K$, except at extremely strong fields when $K$ starts to decrease (see Fig. 6),

2) increase of the layer thickness causes an increase of the average recombination rate (because the charge carriers have to travel a longer distance 
and reach the electrodes in a longer time), and an increase of the multiplication factor (compare Fig. 6(a, b)).

Thus, the changes of the photocurrent due to each of those two processes have the same sign when they are caused by a change of electric field, but opposite signs when they are caused by a change of the layer thickness. The latter fact could be used to check if the electron multiplication effect is present. If an increase of the layer thickness causes a significant increase of the sensitivity, then this would confirm that the fieldstimulated electron multiplication is the main reason of the sensitivity increase. In absence of recombination, the relative change of sensitivity would be equal to the relative change of the multiplication factor. For example, using the parameter value $E_{\min }=0.7 \mathrm{eV}$ in Fig. 6 , an increase of the layer thickness from 12.5 to $25 \mu \mathrm{m}$ would cause an increase of the sensitivity at $F=6 \cdot 10^{6} \mathrm{~V} / \mathrm{m}$ by $36 \%$ (because the ratio of the corresponding $K$ values is $5.448 / 4.010=1.36$ ). If, on the other hand, an increase of the layer thickness causes a decrease of the sensitivity, then this would mean that the field-stimulated electron multiplication is absent or insufficient to overcome the effects of the increased recombination rate.

It should be noted again that all the above is based on the assumption of uniform photogeneration of charge carriers (i.e. constant absorbed dose rate). This assumption is approximately satisfied in the case of a weak absorption of X-rays, and it may be applied in the case of the layers discussed in the present work (they absorb only a few percent of incident X-ray photons at most).

The measured dependence of the sensitivity on electric field strength, which is shown in Fig. 4 for four values of the layer thickness, indicates that the sensitivity increases with layer thickness: an increase of the thickness from 7 to $25 \mu \mathrm{m}$ causes an increase of the sensitivity by a factor greater than 2. As explained above, this confirms that the field-stimulated electron multiplication is the main reason of the sensitivity increase.

\section{Conclusions}

The results of calculations of the electron multiplication factor $K$ in an organic-inorganic blend with tungsten nanoparticles demonstrate that the assumption of existence of a threshold value of electron energy $E_{\text {min }}$, below which the electrons cannot be accelerated by electric field to energies sufficient for impact ionization, leads to a significant departure of the dependence of the electron multiplication factor $K$ on electric field strength $F$ from a simple exponential increase, which is commonly associated with an electron avalanche. In fact, $K$ even starts to decrease when $F$ exceeds a certain value. Since there are no electrons with energy above $E_{\min }$ at the thermodynamic equilibrium at room temperature, the mentioned electron multiplication occurs only under conditions of electron excitation by an external source of energy, such as $\mathrm{X}$-rays in the present work.

The results of measurements of the X-ray sensitivity of $2 \mathrm{CBr}+\mathrm{W}$ layers indicate that the sensitivity (defined as the average charge collected from the unit volume divided by the average absorbed dose) increases with the layer thickness (an increase of the thickness from 7 to $25 \mu \mathrm{m}$ causes an increase of the sensitivity by a factor greater than 2 ). This confirms that the mentioned electron multiplication is the main reason of the sensitivity enhancement, which has been observed after adding tungsten particles into the organic material.

Another factor affecting the X-ray sensitivity is the ionization energy loss of photoelectrons generated inside metallic nanoparticles. This phenomenon has an adverse effect on the sensitivity. As demonstrated by Monte Carlo simulations, when the photoelectrons are mainly generated inside the tungsten nanoparticles with an average diameter of $0.8 \mu \mathrm{m}$ (as is the case with $2 \mathrm{C}+\mathrm{W}$ and $2 \mathrm{Ph}+\mathrm{W}$ ), the corresponding relative decrease of the sensitivity may be as large as $75 \%$. In order to reduce this effect, the size of nanoparticles should be reduced, or, alternatively, most of the photoelectrons should be generated in the organic matrix rather than inside the nanoparticles (as is the case with $2 \mathrm{CBr}+\mathrm{W}$, where the photoelectric absorption of X-rays mainly occurs in $\mathrm{Br}$ atoms).

\section{References}

[1] H. Mescher, E. Hamann, and U. Lemmer, Simulation and design of folded perovskite X-ray detectors, Sci. Rep. 9, 5231 (2019).

[2] L. Li, X. Liu, H. Zhang, B. Zhang, W. Jie, P.J. Sellin, C. Hu, G. Zeng, and Y. Xu, Enhanced X-ray 
sensitivity of $\mathrm{MAPbBr}_{3}$ detector by tailoring the interface-states density, ACS Appl. Mater. Interfaces 11, 7522 (2019).

[3] U. Lemmer and H. Mescher, Novel hybrid organic-inorganic perovskite detector designs based on multilayered device architectures: simulation and design, Proc. SPIE 10948, 10948W (2019).

[4] K.D.G.I. Jayawardena, H.M. Thirimanne, S.F. Tedde, J.E. Huerdler, A.J. Parnell, R.M.I. Bandara, C.A. Mills, and S.R.P. Silva, Millimeter-scale unipolar transport in high sensitivity organic-inorganic semiconductor X-ray detectors, ACS Nano 13, 6973 (2019).

[5] A. Ciavatti, L. Basiricò, I. Fratelli, S. Lai, P. Cosseddu, A. Bonfiglio, J.E. Anthony, and B. Fraboni, Boosting direct $\mathrm{X}$-ray detection in organic thin films by small molecules tailoring, Adv. Funct. Mater. 29, 1806119 (2019).

[6] J. Oliveira, P.M. Martins, V. Correia, L. Hilliou, D. Petrovykh, and S. Lanceros-Mendez, Water based scintillator ink for printed X-ray radiation detectors, Polym. Test. 69, 26 (2018).

[7] H.S. Gill, B. Elshahat, A. Kokil, L. Li, R. Mosurkal, P. Zygmanski, E. Sajo, and J. Kumar, Flexible perovskite-based X-ray detectors for dose monitoring in medical imaging applications, Phys. Med. 5, 20 (2018).

[8] R. Dobužinskas, A. Poškus, and K. Arlauskas, $\mathrm{X}$-ray sensitivity of small organic molecule and zinc cadmium sulfide mixture layers deposited using thermal melting technique, Org. Electron. 18, 37 (2015).

[9] A. Intaniwet, C.A. Mills, M. Shkunov, H. Thiem, J.L. Keddie, and P.J. Sellin, Characterization of thick film poly(triarylamine) semiconductor diodes for direct X-ray detection, J. Appl. Phys. 106, 064513 (2009).

[10]B. Elshahat, H.S. Gill, I. Filipyev, S. Shrestha, J. Hesser, J. Kumar, A. Karellas, P. Zygmanski, and E. Sajo, Technical Note: Nanometric organic photovoltaic thin film detectors for dose monitoring in diagnostic X-ray imaging, Med. Phys. 42, 4027 (2015).

[11]L. Basiricò, A. Ciavatti, T. Cramer, P. Cosseddu, A. Bonfiglio, and B. Fraboni, Direct X-ray photoconversion in flexible organic thin film devic- es operated below 1 V, Nat. Commun. 7, 13063 (2016).

[12]C.W. Han and Y.H. Tak, in: Flat Panel Display Manufacturing (John Wiley \& Sons, Ltd, 2018) pp. 143-158.

[13]H.-W. Chen, J.-H. Lee, B.-Y. Lin, S. Chen, and S.-T. Wu, Liquid crystal display and organic lightemitting diode display: present status and future perspectives, Light Sci. Appl. 7, 17168 (2018).

[14]H. Vartanian and J. Jurikson-Rhodes, Mobile Device with a Flexible Organic Light Emitting Diode (OLED) Multi-touch Display, U.S. Patent Application US20170337858A1 (2017).

[15]N.S. Sariciftci, From organic electronics to bioorganic electronics, Nonlinear Opt. Quantum Opt. 50, 137 (2019).

[16]X. Cai, B. Gao, X.-L. Li, Y. Cao, and S.-J. Su, Singlet-triplet splitting energy management via acceptor substitution: complanation molecular design for deep-blue thermally activated delayed fluorescence emitters and organic light-emitting diodes application, Adv. Funct. Mater. 26, 8042 (2016).

[17]J. Park, S. Lee, and H.H. Lee, High-mobility polymer thin-film transistors fabricated by solvent-assisted drop-casting, Org. Electron. 7, 256 (2006).

[18]H. Yang and P. Jiang, Large-scale colloidal selfassembly by doctor blade coating, Langmuir 26, 13173 (2010).

[19]Y. Yuan, G. Giri, A.L. Ayzner, A.P. Zoombelt, S.C.B. Mannsfeld, J. Chen, D. Nordlund, M.F. Toney, J. Huang, and Z. Bao, Ultra-high mobility transparent organic thin film transistors grown by an off-centre spin-coating method, Nat. Commun. 5, 3005 (2014).

[20]Roll-to-Roll Manufacturing: Process Elements and Recent Advances, eds. J. Greener, G.H. Pearson, and M. Cakmak (Wiley, Hoboken, NJ, 2018).

[21]S. Logothetidis and A. Laskarakis, in: SolutionProcessable Components for Organic Electronic Devices, eds. J. Ulanski, B. Luszczynska, and K. Matyjaszewski (Wiley-VCH Verlag $\mathrm{GmbH}$ \& Co. KGaA, Weinheim, Germany, 2019) pp. 627-653.

[22]F. Pastorelli, T.M. Schmidt, M. Hösel, R.R. Søndergaard, M. Jørgensen, and F.C. Krebs, The organic 
power transistor: roll-to-roll manufacture, thermal behavior, and power handling when driving printed electronics, Adv. Eng. Mater. 18, 51 (2016).

[23]D. Yu, D. Beckelmann, M. Opsölder, B. Schäfer, K. Moh, R. Hensel, P.W. De Oliveira, and E. Arzt, Roll-to-roll manufacturing of micropatterned adhesives by template compression, Materials 12, 97 (2019).

[24]H. Wang, Z. Zeng, P. Xu, L. Li, G. Zeng, R. Xiao, Z. Tang, D. Huang, L. Tang, C. Lai, et al., Recent progress in covalent organic framework thin films: fabrications, applications and perspectives, Chem. Soc. Rev. 48, 488 (2019).

[25]C.S. Kim, S. Lee, E.D. Gomez, J.E. Anthony, and Y.-L. Loo, Solvent-dependent electrical characteristics and stability of organic thin-film transistors with drop cast bis(triisopropylsilylethynyl) pentacene, Appl. Phys. Lett. 93, 103302 (2008).

[26]R. Dobužinskas, A. Poškus, M. Viliūnas, V. Jankauskas, M. Daškevičienè, V. Getautis, and K. Arlauskas, Melt spin coating for X-ray-sensitive hybrid organic-inorganic layers of small carbazolyl-containing molecules blended with tungsten, Phys. Status Solidi A 216(23), 1900635 (2019).

[27]Y. Zhao, X. Zhao, M. Roders, A. Gumyusenge, A.L. Ayzner, and J. Mei, Melt-processing of complementary semiconducting polymer blends for high performance organic transistors, Adv. Mater. 29, 1605056 (2017).

[28]D.B. Mitzi, C.D. Dimitrakopoulos, J. Rosner, D.R. Medeiros, Z. Xu, and C. Noyan, Hybrid field-effect transistor based on a low-temperature melt-processed channel layer, Adv. Mater. 14, 1772 (2002).

[29]S. Kasap, J.B. Frey, G. Belev, O. Tousignant, H. Mani, J. Greenspan, L. Laperriere, O. Bubon, A. Reznik, D. DeCrescenzo, K.S. Karim, and J.A. Rowlands, Amorphous and polycrystalline photoconductors for direct conversion flat panel X-ray image sensors, Sensors 11, 5112 (2011).

[30]A. Intaniwet, C.A. Mills, M. Shkunov, P.J. Sellin, and J.L. Keddie, Heavy metallic oxide nanoparticles for enhanced sensitivity in semiconducting polymer X-ray detectors, Nanotechnology 23, 235502 (2012).

[31]Y. Wang, X. Liu, X. Li, F. Zhai, S. Yan, N. Liu, Z. Chai, Y. Xu, X. Ouyang, and S. Wang, Direct radiation detection by a semiconductive metalorganic framework, J. Am. Chem. Soc. 141, 8030 (2019).

[32]Y.C. Kim, K.H. Kim, D.-Y. Son, D.-N. Jeong, J.-Y. Seo, Y.S. Choi, I.T. Han, S.Y. Lee, and N.-G. Park, Printable organometallic perovskite enables large-area, low-dose X-ray imaging, Nature 550, 87 (2017).

[33]C.A. Mills, H. Al-Otaibi, A. Intaniwet, M. Shkunov, S. Pani, J.L. Keddie, and P.J. Sellin, Enhanced $\mathrm{X}$-ray detection sensitivity in semiconducting polymer diodes containing metallic nanoparticles, J. Phys. Appl. Phys. 46, 275102 (2013).

[34]M. Daskeviciene, V. Getautis, J.V. Grazulevicius, A. Stanisauskaite, J. Antulis, V. Gaidelis, V. Jankauskas, and J. Sidaravicius, Crosslinkable carbazolylcontaining molecular glasses for electrophotography, J. Imaging Sci. Technol. 46(5), 467 (2002).

[35]W.D. Schubert and E. Lassner, Production and characterization of hydrogen-reduced submicron tungsten powders - Part 1: State of the art in research, production and characterization of raw materials and tungsten powders, Int. J. Refract. Met. Hard Mater. 10, 133 (1991).

[36]S. Kutkevicius, A. Stanisauskaite, V. Getautis, A. Railaite, and S. Uss, Synthesis of carbazole containing organic photosemiconductors using dimercapto compounds, J. Prakt. Chem., 337, 315 (1995).

[37]J. Heller, D. Lyman, and W. Hewett, The synthesis and polymerization studies of some higher homologues of 9-vinylcarbazole, Makromol. Chem. 73, 48-59 (1964).

[38] Average Energy Required to Produce an Ion Pair, Report, ICRU-31 (Washington DC, 1979).

[39]S.T. Perkins, D.E. Cullen, and S.M. Seltzer, Tables and Graphs of Electron-Interaction Cross Sections from $10 \mathrm{eV}$ to $100 \mathrm{GeV}$ Derived from the LLNL Evaluated Electron Data Library (EEDL), $Z=1-100$, Technical Report, UCRL-50400Vol. 31, 5691165 (1991). 
[40] K. Irikura, Electron-Impact Cross Section for Ionization and Excitation, NIST Standard Reference Database 107 (National Institute of Standards and Technology, 1997).

[41]D.E. Cullen, J.H. Hubbell, and L. Kissel, EPDL97: The Evaluated Photo Data Library '97 Version, Report, UCRL-50400-Vol. 6-Rev. 5, 295438 (1997).

[42]S.T. Perkins, D.E. Cullen, M.H. Chen, J. Rathkopf, J. Scofield, and J.H. Hubbell, Tables and Graphs of Atomic Subshell and Relaxation Data Derived from the LLNL Evaluated Atomic Data Library (EADL), $Z=1-100$, Report, UCRL-50400Vol. 30, 10121422 (1991).

[43]A. Poškus, Monte Carlo estimation of average energy required to produce an ion pair in noble gases by electrons with energies from $1 \mathrm{keV}$ to $100 \mathrm{MeV}$, J. Nucl. Sci. Technol. 52, 675 (2015).

\title{
ORGANINIU RENTGENO SPINDULIUOTĖS DETEKTORIUU JAUTRUMO PADIDINIMO SU VOLFRAMO NANODALELĖMIS FIZINIS MECHANIZMAS
}

\author{
A. Poškus, R. Dobužinskas, M. Viliūnas, K. Arlauskas \\ Vilniaus universiteto Cheminès fizikos institutas, Vilnius, Lietuva
}

\section{Santrauka}

Pateiktas paprastas teorinis modelis, paaiškinantis padidejusị rentgeno spindulių jautrị įterpus volframo nanodalelių ì plonus organinių medžiagų sluoksnius. Jautrio padidèjimą lemia elektronų dauginimas dèl antrinès elektronu emisijos iš volframo dalelių. Atlikus keletą supaprastinančių prielaidų, išvedama elektronų dauginimo faktoriaus $K$ išraiška tuo atveju, kai volframo atomai yra tolygiai pasiskirstę matricos medžiagoje. Pagrindinè modelio prielaida yra $0,1 \mathrm{eV}$ eilès energijos slenkstinè vertė $E_{\min }$,̌emiau kurios krūvininkų rekombinacija neleidžia jiems elektriniame lauke pagreitèti iki energijų, pakankamų smūginei jonizacijai. İrodyta, kad, galiojant šiai prielaidai, $K$ ir rentgeno spinduliuotès su- kurtos srovès padidejimas stiprèjant elektriniam laukui yra daug lètesnis nei eksponentinis (ịprastai susijęs su elektronu griūtimi), ir $K$ gali netgi pradèti mažèti, kai elektrinio lauko stipris viršija tam tikrą vertę. Kitas veiksnys, darantis neigiamą ittaką rentgeno spindulių jautriui, yra fotoelektronų jonizaciniai energijos nuostoliai volframo nanodalelèse. Monte Karlo modeliavimo rezultatai rodo, kad esant $0,8 \mu \mathrm{m}$ skersmens sferinems volframo dalelèms dèl pastarojo reiškinio jautris gali papildomai sumažèti $75 \%$. Norint sumažinti ši poveiki reikètu sumažinti nanodalelių dydị arba didžioji dalis fotoelektronų turètų būti generuojami ne nanodalelèse, o organinèje matricoje. 